\title{
Parathyroid cyst- missed diagnosis or a misdiagnosis: A case report
}

\author{
Ranjana Hawaldar, ${ }^{1, *}$, Sadhna Sodani ${ }^{2}$, R. K. Sodani ${ }^{3}$, Nitin Jadhav ${ }^{4}$ \\ ${ }^{1}$ Consultant Pathologist, Dept. of Pathology, Sampurna Sodani Diagnostic Clinic, Indore, Madhya Pradesh, ${ }^{2}$ Associate Professor, \\ Dept. of Microbilogy, MGM Medical College, (Devi Ahilya University, Indore) Indore, Madhya Pradesh, ${ }^{3,4}$ Consultant \\ Sonologist, Sampurna Sodani Diagnostic Clinic, Indore, Madhya Pradesh, India
}

*Corresponding Author:

Email: drranjana@sampurnadiagnostics.com

\begin{abstract}
Introduction: The neck swellings, specially of cystic nature, may be of thyroid origin, thymic cysts, thyroglossal duct cysts, branchial cleft cysts, bronchogenic cysts or lymphangiomas depending upon the site of origin. Parathyroid cysts constitute 0.5$1 \%$ of all neck cysts and are a rare entity. A strong index of suspicion is required for its correct diagnosis.

Here, we report a case of parathyroid cyst in a 40 year old female and the clinicopathological findings which posed a diagnostic challenge, thus highlighting the importance of including parathyroid cysts in the differential diagnosis of neck cysts.

Case Report: Fine needle aspiration was performed on the swelling and approximately $20 \mathrm{ml}$ of watery, crystal clear fluid was aspirated from the cyst. Cytological examination was acellular. The fluid PTH level was $23.6 \mathrm{pg} / \mathrm{ml}$, serum calcium was 8.6 $\mathrm{mg} / \mathrm{dl}$ (normal reference range 8.5-10.1 mg/dl) and serum PTH level was $65.88 \mathrm{pg} / \mathrm{ml}$ (normal reference range $15-65 \mathrm{pg} / \mathrm{ml}$.

Conclusion: Parathyroid cysts are uncommon benign cystic lesions and may be functional or non functional in nature. FNA is a valuable diagnostic tool along with fluid PTH level. The parathyroid cysts should be included in the differential diagnosis of all anterior cystic neck swellings so that they are not missed or misdiagnosed as thyroid lesions.
\end{abstract}

Keywords: Parathyroid cysts, PTH, FNAC, USG.

\section{Introduction}

Neck swellings are common in day to day medical practice and are subjected to fine needle aspiration for diagnostic and therapeutic purposes. The neck swellings, specially of cystic nature, may be of thyroid origin, thymic cysts, thyroglossal duct cysts, branchial cleft cysts, bronchogenic cysts or lymphangiomas depending upon the site of origin.

The first description of parathyroid cysts dates back to 1880 when Sandstorm, a Swedish anatomist described it and Goris, a Belgian surgeon was the first surgeon to remove a parathyroid cyst. ${ }^{1,2}$ Till date about 300 cases of parathyroid cysts have been reported in literature. $^{3,4}$ Parathyroid cysts constitute $0.5-1 \%$ of all neck cysts and are a rare entity. ${ }^{5}$ A strong index of suspicion is required for its correct diagnosis.

Parathyroid cysts may be functional or non functional depending on their ability to secrete parathyroid hormone. Physical examination of these neck swellings are nonspecific and a preoperative diagnosis is often not possible as these are most often confused with thyroid nodules. ${ }^{6-10} \mathrm{E}$ arlier, these cysts were diagnosed on histopathological examination but nowadays, with the help of ultrasound and fine needle aspiration cytology, they are being diagnosed preoperatively also.

The diagnosis of Parathyroid cysts is clinched when a watery, crystal clear fluid is aspirated from a neck swelling and is confirmed by an elevated parathyroid hormone level in the cyst fluid. ${ }^{7-9,11}$

Here, we report a case of parathyroid cyst in a 40 year old female and the clinicopathological findings which posed a diagnostic challenge, thus highlighting the importance of including parathyroid cysts in the differential diagnosis of neck cysts.

\section{Case Report}

A 40 year old female patient presented to our diagnostic centre with complains of anterior neck swelling since two years. On examination, the swelling was diffuse, in the region of the thyroid gland and moved with deglutition. A presumptive diagnosis of a thyroid swelling was made clinically. There was no dyspnoea, change in voice or swallowing difficulty. Ultrasound of the neck showed right lobe of thyroid measuring: $3.5 \times \quad$ x $0.8 \quad$ x $1.4 \quad \mathrm{~cm}$ with normal parenchymal echoes.

Both submandibular and parotid glands were unremarkable on B mode sonography. Left CCA \& IJV we re displaced laterally by the enlarged left lobe of thyroid, with normal vascularity on colour Doppler. No focal lesion was seen. Left lobe of thyroid was enlarged in size \& measured 8.3 x $6.1 \times 6.2 \mathrm{~cm}$. Parenchyma echoes were normal with normal vascularity on color Doppler. A $7.1 \times 5.6 \times 5.8 \mathrm{~cm}$ sized large exophytic cystic lesion w a seen in the left lobe near the lower pole which showed very few echoes within. No solid component or septations we re seen within. No calcifications we re seen within the nodule. Isthmus was normal $(2 \mathrm{~mm})$. No significantly enlarged lymph nodes were seen in bilateral neck region. No abnormal vascularity was noted in neck on color Doppler study. An impression of a large exophytic cystic lesion in the left lobe of thyroid gland with a differential diagnosis of a simple cyst / 
colloid cyst was made on ultrasound and an FNAC was advised (see Fig. 1 to 3 ).

Fine needle aspiration was performed on the swelling and approximately $20 \mathrm{ml}$ of watery, crystal clear fluid was aspirated from the cyst. (Fig. 4) Cytological examination was a cellular. Presumptive diagnosis of parathyroid cyst was made and a fluid PTH and serum calcium and serum PTH levels were requested. The fluid PTH level was $23.6 \mathrm{pg} / \mathrm{ml}$, serum calcium was $8.6 \mathrm{mg} / \mathrm{dl}$ (normal reference range 8.5-10.1 $\mathrm{mg} / \mathrm{dl}$ ) and serum PTH level was $65.88 \mathrm{pg} / \mathrm{ml}$ (normal reference range $15-65 \mathrm{pg} / \mathrm{ml}$ ).

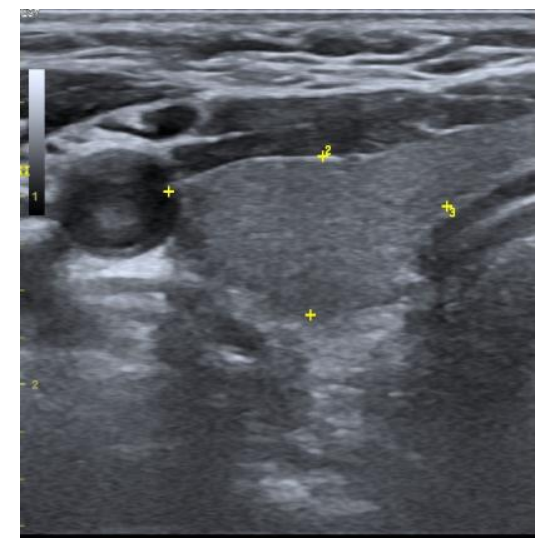

Fig. 1: USG of thyroid

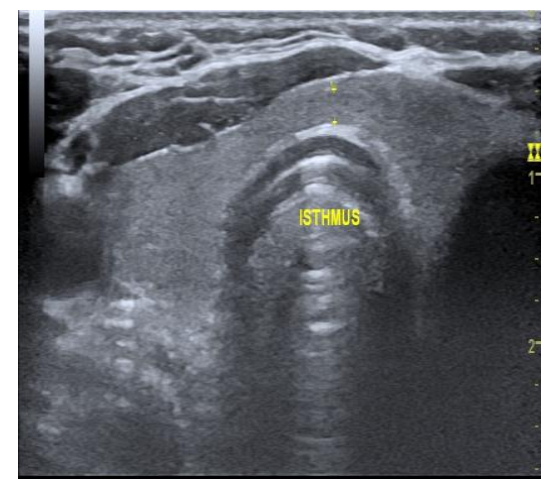

Fig. 2: USG of isthmus

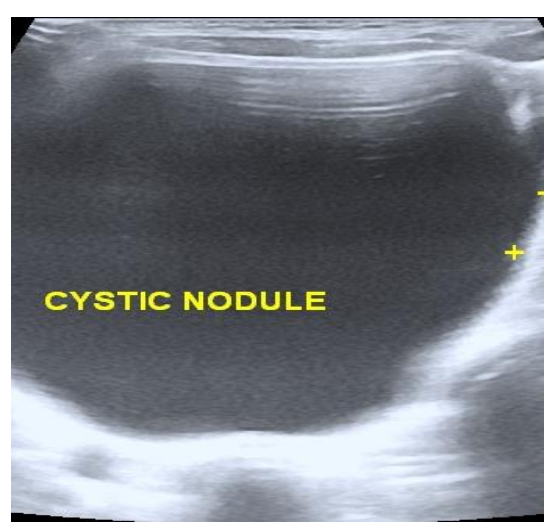

Fig. 3: USG of cystic nodule

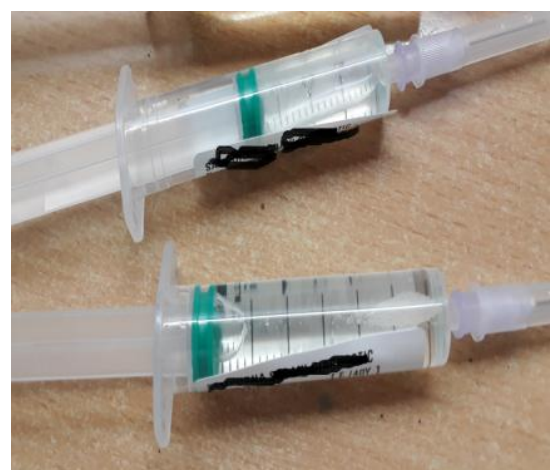

Fig. 4 showing fluid aspirated from cyst

\section{Discussion}

Parathyroid cysts are a rare entity and are often misdiagnosed as thyroid lesions in the absence of FNAC and may often be missed. $80 \%$ of the parathyroid cysts are solitary and non functional and present as neck swellings anterior to the inferior pole of the thyroid gland. ${ }^{12}$ In embryonic stage, the superior parathyroid glands are closely related to the thyroid gland while inferior parathyroid glands are related to the thymus. This is clinically significant because parathyroid cysts have a propensity to occur anywhere in the neck and mediastinum and may mimic a thyroid or a mediastinal mass.

The pathogenesis of parathyroid cysts is still unclear but several theories have been proposed. One theory proposes that these cysts result from a vestigeal remnant of the third or fourth branchial cleft or from the persistent Kursteiner canals. ${ }^{13}$ Other theory proposes that it results from the infarction and degeneration of a parathyroid adenoma or due to coalescence of multiple small cysts present in the parathyroid gland. ${ }^{12}$

A thorough head and neck examination along with a FNAC and USG can be helpful in arriving at a diagnosis. FNA yields a clear, colourless, watery fluid. A raised fluid PTH level is confirmatory. ${ }^{14,15}$ A raised fluid PTH level, however does not necessarily correlate with the functional activity of the lesion but is a valuable diagnostic tool for all cystic neck swellings, especially when there is an element of doubt in the diagnosis. FNA of the thyroid cysts yields a cloudy, gelatinous or bloody aspirate in which PTH is undetectable. ${ }^{16}$

Anand G. et al reported a case of parathyroid cyst in a 44 year female. $^{17}$ A. Guner et al reported parathyroid cyst in a 56 year female with a left sided cervical lump. $^{18}$

Non functional cysts are more common in females with a male to female ratio of $1: 2.5$, usually presenting in the fourth and fifth decade of life and often originating from inferior parathyroid glands. ${ }^{19} 10 \%$ of the parathyroid cysts are functional and have a male preponderance with elevated PTH levels and hypercalcaemia. ${ }^{20}$ Non functional cysts often have 
compression symptoms while functional cysts are associated with symptoms of hyperparathyroidism. ${ }^{21}$

USG may sometimes be helpful in diagnosing these lesions but often reveal a non specific cysytic structure as was evident in our case. Ujiki et al in their study observed that USG was seldom able to diagnose parathyroid cysts with certainity. ${ }^{22} \mathrm{CT}$ scan and MRI may help in visualizing the relationship of these cysts with the adjacent tissues.

The treatment of parathyroid cysts is controversial. Some authors suggest complete therapeutic removal of cystic fluid. ${ }^{23}$ The success rate of this option ranges from $33 \%$ to $92 \% .^{24-27}$ Prinz et al proposed initial aspiration followed by tetracycline sclerosis after a second recurrence. ${ }^{24}$ If these two treatment modalities fail, surgical removal of the lesion is the only option left. Histopathologically, parathyroid cysts consist of smooth internal layer with a thin membranous layer. The cyst wall is lined by a single layer of cuboidal or columnar epithelium positive for glycogen. ${ }^{28}$ It is usually loosely attached to the thyroid on gross examination. Intaoperative rupture of the parathyroid cysts may lead to parathyromatosis. ${ }^{29}$

Post operative monitoring of calcium levels is mandatory as hypocalcemia can occur after parathyroid cyst excision.

\section{Conclusion}

Parathyroid cysts are uncommon benign cystic lesions and may be functional or non functional in nature. FNA is a valuable diagnostic tool along with fluid PTH level. The parathyroid cysts should be included in the differential diagnosis of all anterior cystic neck swellings so that they are not missed or misdiagnosed as thyroid lesions.

\section{Conflict of Interest: None}

\section{References}

1. Sandstrom I, 1880 Om en kortel hos mennishkan och atskilliga doggdjus. Ups Lakafor Forhandl 14:441-471.

2. Goris D, 1905 Extirpation de trios lobules parathyroidens kystiques. Ann Soc Belge Chir 5:394-400.

3. Alvi A, Myssiorek D, Wasserman P, 1996 Parathyroid cysts: current diagnostic and management principles. Head Neck 18:370-373.

4. Braccini F, Epron JP, Roux C, et al, 2000 Essential parathyroid cysts: a misleading lesion. Rev Laryngol Otol Rhinol (Bord) 121: 165-168.

5. Cappelli C, Rotondi M, Pirola I, et al, 2009 Prevalence of parathyroid cysts by neck ultrasound scan in unselected patients. J Endocrinol Invest 32:357-359.

6. Clark OH: Parathyroid cysts. Am J Surg 1978;135:395402.

7. DeRaimo AJ, Kane RA, Katz JF, Rolla AP: Parathyroid cysts: Diagnosis by sonography and needle aspiration. AJR 1984;142:1227-1228.

8. Katz AD, Dunkleman D: Needle aspiration of nonfunctioning parathyroid cysts. Arch Surg 1984;119:307-308.
9. Marco V, Carrasco MA, Marco C, Bauza A: Cytomorphology of a mediastinal parathyroid cyst. Report of a case mimicking malig nancy. Acta Cytol 1983;27:688-692.

10. Rosenberg J, Orlando R, Ludwig M, Pyrtek U: Parathyroid cysts. Am J Surg 1982;143:473-480.

11. Margolis 18, Organ CH: Parathyroid cysts: Functional and mediastinal. Surgery 1975;77:462-466.

12. N. Pontikides, S. Karras, A. Kaprara et al., "Diagnostic and therapeutic review of cystic parathyroid lesions," Hormones, vol. 11, no. 4, pp. 410-418, 2012.

13. E. D. Rossi, L. Revelli, E. Giustozzi et al., "Large nonfunctioning parathyroid cysts: our institutional experience of a rare entity and a possible pitfall in thyroid cytology," Cytopathology, vol. 26, no. 2, pp. 114-121, 2015.

14. S. L. Lee, "Parathyroid cyst fluid: discrepancy between C-terminal and intact parathyroid hormone assays," Thyroid, vol. 10, no. 12, pp. 1125-1126, 2000.

15. A. Guner, S. Karyagar, O. Ozkan, C. Kece, and E. Reis, "Parathyroid cyst: the forgotten diagnosis of a neck mass," Journal of Surgical Case Reports, vol. 8, no. 4, pp. $1-4,2011$.

16. F. Pacini, A. Antonelli, R. Lari, L. Gasperini, L. Baschieri, and A. Pinchera, "Unsuspected parathyroid cysts diagnosed by measurement of thyroglobulin and parathyroid hormone concentrations in fluid aspirates," Annals of Internal Medicine, vol. 102, no. 6, pp. 793-794, 1985.

17. Anand Goomany, Amy Rafferty, and Ian Smith an Unusual Neck Mass: A Case of a Parathyroid Cyst and Review of the Literature Case Reports in Surgery, Volume 2015:4.

18. A Guner, S Karyagar, O Ozkan, C Kece, and E Reis Parathyroid cyst: the forgotten diagnosis of a neck mass J Surg Case Rep. 2011 Aug; 2011(8): 4.

19. D. A. da Silva, M. C. Machado, L. L. Brito, R. A. Guimarães, A. S. Fava, and M. C. A. C. Mamone, "Parathyroid cysts: diagnosis and treatment," Revista Brasileira de Otorrinolaringologia, vol. 70, no. 6, pp. 840-844, 2004.

20. G. Ippolito, F. F. Palazzo, F. Sebag, M. Sierra, C. de Micco, and J. F. Henry, "A single-institution 25-year review of true parathyroid cysts," Langenbeck's Archives of Surgery, vol. 391, no. 1, pp. 13-18, 2006.

21. J. K. Fortson, V. G. Patel, and V. J. Henderson, "Parathyroid cysts: a case report and review of the literature," Laryngoscope, vol. 111, no. 10, pp. 17261728, 2001.

22. M. Ujiki, C. Sturgeon, R. Nayar, and P. Angelos, "Parathyroid cyst: often mistaken for a thyroid cyst," World Journal of Surgery, vol. 32, no. 6, p. 1234, 2008.

23. O. H. Clark, "Parathyroid cysts," The American Journal of Surgery, vol. 135, no. 3, pp. 395-402, 1978.

24. R. A. Prinz, J. R. Peters, J. M. Kane, and J. Wood, "Needle aspiration of nonfunctioning parathyroid cysts," The American Surgeon, vol. 56, no. 7, pp. 420422, 1990.

25. B. Shi, H. Guo, and N. Tang, "Treatment of parathyroid cysts with fine-needle aspiration," Annals of Internal Medicine, vol. 131, no. 10, pp. 797-798, 1999.

26. T. Kodama, T. Obara, Y. Fujimoto, Y. Ito, T. Yashiro, and A. Hirayama, "Eleven cases of nonfunctioning parathyroid cyst-significance of needle aspiration in diagnosis and management," Endocrinologia Japonica, vol. 34, no. 5, pp. 769-777, 1987. 
27. K. Okamura, H. Ikenoue, K. Sato et al., "Sclerotherapy for benign parathyroid cysts," The American Journal of Surgery, vol. 163, no. 3, pp. 344-345, 1992.

28. K. S. Lerud, S. O. Tabbara, D. M. DelVecchio, and A. R. Frost, "Cytomorphology of cystic parathyroid lesions: report of four cases evaluated preoperatively by fineneedle aspiration," Diagnostic Cytopathology, vol. 15, no. 4, pp. 306-311, 1996.

29. K. L. McCoy, J. H. Yim, B. S. Zuckerbraun, J. B.

Ogilvie, R. L. Peel, and S. E. Carty, "Cystic parathyroid lesions: functional and nonfunctional parathyroid cysts," Archives of Surgery, vol. 144, no. 1, pp. 52-56, 2009. 